\title{
CAUSAL ATTRIBUTIONS OF SUCCESS AND FAILURE AND MOOD STATES IN FOOTBALL PLAYERS
}

\author{
JOANNA SZCZEPANIAK1, MONIKA GUSZKOWSKA² \\ 1Doctoral Studies, Józef Pitsudski University of Physical Education in Warsaw, Faculty of Physical Education \\ 2Józef Pitsudski University of Physical Education in Warsaw, Faculty of Rehabilitation, \\ Department of Clinical Psychology and Special Education
}

\begin{abstract}
Mailing address: Joanna Szczepaniak, Józef Piłsudski University of Physical Education in Warsaw, 34 Marymoncka Street, 00-986 Warsaw, tel.: +48 504789459, fax: +48 22 8651080, e-mail: asialeszcz@gmail.com
\end{abstract}

\begin{abstract}
Introduction. The aim of the study was to determine the causal attributions of success and failure in a football match in a group of football players, as well as to investigate the association of the players' attributions with their level of achievement and the relationships between their causal attributions and affective states. Material and methods. The study involved 75 football players, including 44 players from the first league and 31 players from the third league. The research was carried out using the Profile of Mood States (POMS) by D.M. McNair, M. Lorr, and L.F. Droppleman and a specially designed questionnaire concerning the causal attributions of success and failure. Results. It was found that the football players who participated in the study tended to attribute success to internal causes and failure to external causes. More frequent use of external attributions most likely had an adverse impact on the mood state of the players. Conclusion. Information concerning the attributions that a given player makes can be useful for coaches, as it can help them develop the athlete's mental abilities more effectively. Beliefs related to attributions can be modified. It is worth considering the benefits of encouraging internal attributions in the case of success and external attributions in situations of failure.
\end{abstract}

Key words: football, causal attributions, mood states, emotions

\section{Introduction}

The successful performance of a football team depends on many different factors. The factors which are given the most attention are those strictly having to do with sports-related skills. Failure is frequently attributed to inappropriate training methods used by coaches, and psychological aspects are often ignored. If psychological aspects are considered, then the focus in mainly on pre-competition states or emotions which are experienced during the match. However, what happens after the match has finished is also important, as both cognitive and emotional factors can have a major impact on future outcomes.

This article is focused on the attributions of success and failure in sporting events. Attributions are the beliefs that a player holds regarding what caused the match to end in a win, loss, or draw. This issue is important, since, although an athlete's activity is, in principle, conscious and purposeful, athletes do not always attribute a particular action and their effectiveness or ineffectiveness in a sporting event to themselves [1, 2].

Weiner [3] created an attribution model which is based on two factors: the locus of causality (internal and external attributions) and the stability of causality (stable and unstable attributions). Four causal categories have been proposed: internalstable (the athlete's aptitudes and abilities), internal-unstable (effort made during the competition, training before the competition), external-stable (difficulty of the task), and externalunstable (luck, weather conditions, the refereeing, the viewers, etc.).

Lau and Russell [4] found that both coaches and athletes tended to associate success with the features of the team or its members, but they attributed failure to external circumstances (such as a lack of luck or a better performance of the competitors). Moreover, other authors noted that athletes who had won made internal and stable attributions more frequently than those who had lost $[5,6,7]$.

Mroczkowska [8] whose research involved a basketball, volleyball, and handball team observed that the players of each of these teams attributed failure to external factors which were beyond their control. There were also significant differences between teams with better and worse team play: they had different perceptions of the cause that they could control (effort) and the one that they could not control (luck).

Causal attributions of success and failure in sports have a significant influence on athletes' cognitive and emotional states. Attributing failure to factors that can be controlled seems to be conducive to maintaining self-confidence $[9,10]$.

The locus of the causes of the outcome achieved (internal and external attribution) is associated with particular emotions (contentment with success or shame at losing). What is more, assigning the outcome to internal causes (aptitudes, effort) triggers more intense emotions than assigning it to external factors (luck). Athletes who believe that they achieved success owing to their intense effort feel more pride, joy, and satisfaction than those who associate it with factors which were beyond their control (e.g. luck) [1].

Graham et al. [11] observed that sports participants experienced more positive emotions if they made attributions which were stable and personally controllable. Biddle and Hill [12], on the other hand, found that when sports participants attributed success to internal factors, they felt more positive emotions, 
and they experienced negative emotions more intensely if they thought their failure was due to external factors. Later research by Biddle and Hill showed that after a winning performance in laboratory conditions, fencers felt satisfaction, pleasure, and contentment, whereas after a losing performance, they experienced dissatisfaction and disappointment [6]. Allen et al. [13], who explored the relationship between attributions and the level of anger, observed that athletes felt angry for a longer period of time if they attributed the cause of their poor performance to a stable factor.

Attributions, that is the beliefs of the player, team, or coach regarding what contributed to success or failure, can be consciously developed and modified. The ability of coaches to work with players so as to help them attribute the outcomes of sporting events to internal rather than external factors plays a significant role is sports [14]. In a study by Allen et al. [15], it was observed that providing athletes with simple positive feedback after the competition contributed to their developing causal attributions regarding a particular outcome which were more internal in nature. Research by Rascle et al. [16], on the other hand, found that attributional feedback effects were long-term and cross-situational. Coffee and Rees [17] have suggested that it is worth analysing athletes' attributions when they perform successfully, as this can help gain a better understanding of the relationships between attributions and self-efficacy.

To sum up, after winning or losing a match, a football player spontaneously makes causal attributions regarding its outcome. The results of previous studies indicate that in the case of failure, external attributions are more frequent, whereas with successful outcomes, internal ones are more common. These attributions should be of interest to researchers, coaches, and psychologists for at least three reasons. First of all, they are linked with postmatch emotional states, which, in turn, co-determine the affective states experienced by a player before the following match. Secondly, they have consequences for a player's motivation, either encouraging them to train or discouraging them from training. Thirdly, since they are beliefs, they can be subject to deliberate interventions as athletes are being prepared mentally for sporting events. For all these reasons, attributions and their relationships with post-match emotions should be researched. Thus the aim of our study was to determine the attributions of success and failure in a match in a group of football players as well as to explore the dependence of these attributions on the players' level of achievement and their relationships with postmatch emotional states.

\section{Material and methods}

The study involved 75 male football players (from four senior teams), aged 18-33 years. Two of the teams were in the first league (44 players), and the two remaining ones were in the third league (31 players). The mean age of the players was 23.09 $( \pm 4.68)$ years. A purposive sampling procedure was used.

The research instrument applied in the study was the Polish adaptation of the Profile of Mood States (POMS) by D.M. McNair, M. Lorr, and L.F. Droppleman created by Dudek and Koniarek [18], which makes it possible to determine the intensity of seven affective states, including five negative ones (tension, depression, anger, fatigue, and confusion) and two positive ones (vigour and friendliness). POMS consists of 65 adjectives which describe various feelings and moods that can be experienced. In the instructions, the respondents can be asked to describe their feelings and moods over various periods of time (such as the past day or week). The tool is sensitive to changes that take place over time. In our study, the football players were requested to describe their mood in the past week including the day when the questionnaire was completed. It is worth mentioning that the reliability coefficient and construct validity of the Polish adaptation of the tool are satisfactory.

Moreover, for the purposes of the study, we also designed two scales for investigating the causes of the outcome of the match (win or loss). In the questionnaire concerning the causes of success, the players chose three out of the following ten causes: adequate training before the match, adequate effort put into the match, strong football skills, luck, poor performance of the competitors, supportive viewers, favourable weather conditions, favourable refereeing, better team play than that of the competitors, and financial rewards. In the questionnaire concerning the causes of failure, the players chose three out of the following ten causes: inadequate training before the match, inadequate effort put into the match, weak football skills, lack of luck, poor performance of the competitors, unsupportive viewers, unfavourable weather conditions, unfavourable refereeing, worse team play than that of the competitors, and inadequate financial rewards.

The football players' mood states and causal attributions were examined twice: after they won an important match and after they lost an important match. The questionnaires were completed during the first training session after the match. The time interval between the match and the completion of the questionnaire was the same for every match. Both first and reserve team players took part in the study. In order to explore the relationships between the variables, we calculated Spearman's rho correlation coefficients using the SPSS statistical package (v. 20).

\section{Results}

As already mentioned above, the subjects could choose from among 10 causes of success. The total number of responses for each of the causes is shown in table 1 . The players most often attributed winning outcomes to the following causes in the order of frequency: adequate effort put into the match, better team play than that of the competitors, adequate training, and strong football skills. This means they made internal attributions.

Table 1. Causal attributions of success in the football players

\begin{tabular}{|l|c|c|}
\hline & $\begin{array}{c}\text { Number of } \\
\text { responses }\end{array}$ & Rank \\
\hline 1. Adequate training & 29 & 3 \\
\hline 2. Adequate effort put into the match & 56 & 1 \\
\hline 3. Strong football skills & 28 & 4 \\
\hline 4. Luck & 19 & $5-7$ \\
\hline 5. Poor performance of the competitors & 19 & $5-7$ \\
\hline 6. Supportive viewers & 19 & $5-7$ \\
\hline 7. Adequate weather conditions & 2 & 9 \\
\hline 8. Favourable refereeing & 1 & 10 \\
\hline 9. Better team play than that of the competitors & 40 & 2 \\
\hline 10. Financial rewards & 12 & 8 \\
\hline
\end{tabular}

The responses given with regard to failure are shown in table 2 . The subjects most frequently indicated that the losing outcome had been caused by a lack of luck (external attribution), then inadequate effort put into the match (internal at- 
tribution), and finally a better performance of the competitors (external attribution). Therefore, the players mostly attributed their failure to external causes.

Table 2. Causal attributions of failure in the football players

\begin{tabular}{|l|c|c|}
\hline & $\begin{array}{c}\text { Number of } \\
\text { responses }\end{array}$ & Rank \\
\hline 1. Inadequate training & 22 & 4 \\
\hline 2. Inadequate effort put into the match & 31 & 2 \\
\hline 3. Weak football skills & 18 & $6-7$ \\
\hline 4. Lack of luck & 51 & 1 \\
\hline 5. Very good performance of the competitors & 30 & 3 \\
\hline 6. Unsupportive viewers & 21 & 5 \\
\hline 7. Unfavourable weather conditions & 17 & 8 \\
\hline 8. Unfavourable refereeing & 18 & $6-7$ \\
\hline 9. Worse team play than that of the competitors & 10 & 9 \\
\hline 10. Inadequate financial rewards & 7 & 10 \\
\hline
\end{tabular}

Total attribution scores were calculated by assigning the value of 1 to external attributions and the value of -1 to internal ones and then adding them up. Thus the attribution scores for success and failure could range from -3 (all attributions were internal) to 3 (all attributions were external). In the case of success, the mean was equal to $-1.08(\mathrm{SD}=2.12)$, and as far failure is concerned, it was $0.87(\mathrm{SD}=2.29)$.

Based on these scores, we divided the subjects into three groups: subjects with an internal attribution pattern (with a score of -3), those with an external attribution pattern (3), and those with a mixed attribution pattern (with the values of -1 and 1). The numbers of subjects in particular groups are shown in table 3 . When it comes to success, the greatest number of subjects exhibited an internal attribution pattern, and the smallest number had an external attribution pattern. The reverse was observed for failure.

Table 3. Locus of the causal attributions of success and failure in the football players

\begin{tabular}{|c|c|c|c|c|}
\hline \multirow{2}{*}{} & \multicolumn{2}{|c|}{ Success } & \multicolumn{2}{c|}{ Failure } \\
\cline { 2 - 5 } & $\mathrm{n}$ & $\%$ & $\mathrm{n}$ & $\%$ \\
\hline External & 10 & 13.3 & 30 & 40.0 \\
\hline Mixed & 32 & 42.7 & 29 & 38.7 \\
\hline Internal & 33 & 44.0 & 16 & 21.3 \\
\hline
\end{tabular}

We also compared the attributions of the first and third league players (tab. 4). The differences between the distributions of the two samples were examined using a chi-squared test. As far as success is concerned, most of the first league players displayed a mixed attribution pattern, whereas third league players tended to have an internal attribution pattern; however, the differences were not statistically significant ( chi square $=4.023$; $\mathrm{p}>0.05$ ). In the case of failure, first league players tended to exhibit external and mixed attribution patterns, while third league players mostly had external attribution patterns. Similarly as in the case of success, the differences were not statistically significant ( chi square $=0.656 ; \mathrm{p}>0.05)$.
Table 4. Comparison of the attributions of the first and third league football players

\begin{tabular}{|c|c|c|c|c|c|}
\hline \multirow{2}{*}{ Attribution } & \multirow{2}{*}{ League } & \multicolumn{2}{|c|}{ Success } & \multicolumn{2}{c|}{ Failure } \\
\cline { 2 - 6 } & & $\mathrm{n}$ & $\%$ & $\mathrm{n}$ & $\%$ \\
\hline \multirow{2}{*}{ External } & 1 & 5 & 11.36 & 18 & 40.91 \\
\cline { 2 - 6 } & 3 & 5 & 16.13 & 12 & 38.71 \\
\hline \multirow{2}{*}{ Mixed } & 1 & 23 & 52.27 & 18 & 40.91 \\
\cline { 2 - 6 } & 3 & 9 & 29.03 & 11 & 35.48 \\
\hline \multirow{2}{*}{ Internal } & 1 & 16 & 36.36 & 8 & 18.18 \\
\cline { 2 - 6 } & 3 & 17 & 54.83 & 8 & 25.80 \\
\hline
\end{tabular}

In order to determine the relationships between mood states and attributions, we calculated Spearman's rank correlation coefficients (tab. 5). We found positive correlations between external causal attributions of success and the levels of anger and depression.

Table 5. Correlations between emotional states and attributions in the football players

\begin{tabular}{|c|c|c|}
\hline & $\begin{array}{c}\text { External attributions of } \\
\text { success }\end{array}$ & $\begin{array}{c}\text { External attribu- } \\
\text { tions of failure }\end{array}$ \\
\hline Anger & $\mathbf{0 . 2 2 6 ^ { * }}$ & $\mathbf{0 . 2 6 6 ^ { * }}$ \\
\hline Confusion & -0.061 & $\mathbf{0 . 3 4 9 ^ { * * }}$ \\
\hline Depression & $\mathbf{0 . 2 4 0 ^ { * }}$ & $\mathbf{0 . 2 5 7 ^ { * }}$ \\
\hline Fatigue & 0.143 & $\mathbf{0 . 2 3 0 ^ { * }}$ \\
\hline Tension & 0.191 & 0.164 \\
\hline Vigour & -0.110 & $-0.227^{*}$ \\
\hline Friendliness & -0.224 & $-0.306^{* *}$ \\
\hline
\end{tabular}

${ }^{*}=\mathrm{p}<0.05 ;{ }^{* *}=\mathrm{p}<0.01$

More statistically significant correlations were observed for the causal attributions of failure. The more external the attributions of failure were, the higher the level of negative mood states (anger, confusion, depression, and fatigue) was and the lower the level of positive mood states (vigour and friendliness) was. To sum up, the more external the attributions tended to be, the worse the affective states of the subjects were, regardless of the outcome of the match.

\section{Discussion}

The football players who participated in the study tended to attribute success to internal causes and failure to external causes. The results of previous research by other authors are comparable to a certain extent in this respect $[6,7,8,19]$. It can be expected that in similar situations these players would be likely to perceive their own skills, aptitudes, or effort as the cause of their success and to see failure as caused by factors beyond their control. Such attributions are conducive to increasing one's selfesteem and positive self-assessment or keeping them at a high level. In the case of success, believing that they have put in adequate effort and have adequate skills makes an athlete feel satisfied with their abilities and convinces them that they can be successful in the future. In situations of failure, shifting the responsibility to external factors which are beyond the athlete's control can help them reduce the feeling of dissatisfaction and makes it less likely that they will become convinced that such 
a dissatisfying outcome will occur again; this is something that could happen if they attributed failure to internal causes [20].

Being able to properly assess the causes of a given outcome in sports is useful in analysing an athlete's performance in a given event. It also makes it possible to maintain better control over their performance in future events and plan it more effectively, as well as protecting the athlete's self in the case of failure, as it is much easier to attribute a poor outcome to external factors (lack of luck) than to internal factors (inadequate effort put into the match).

Our analysis of the relationships between attributions and affective states showed that the more the players attributed their failure to external factors, the worse their mood was. Comparable findings have been reported by other authors [6, 12]. We also observed that external attributions of success were associated with a worse affective state after a match was won. Similarly, Graham et al. [11] found that sport participants felt more positive emotions when they attributed their outcomes to factors which were stable and more controllable, that is to internal factors.

After losing performances, the players tended to attribute the causes of the poor outcome to factors which they were unable to control, and this helped them shift the responsibility away from themselves. This likely improved their mood temporarily, but it did not help solve the problem and in the end, their affective state was worse. It is worth emphasising, however, the role of the outcome itself: since it was negative regardless of the interpretation of its causes, it could have caused the players to have a negative affective state.

Attributing success to external causes may be due to a low level of confidence in one's abilities and a belief that one is not useful for the team. In such cases, a player is not satisfied with their performance, and they may also not be convinced that they can achieve success in the future, which can intensify negative mood states.

Therefore, our findings have only partially confirmed our expectations based on the results of previous studies, which showed that external attributions were associated with better mood after matches that had been lost and worse mood after those that had been won. External attributions were positively correlated with negative emotional states and negatively correlated with positive emotional states, regardless of the outcome of the match. At this point, it is difficult to explain why external attributions of failure, which were definitely defensive in nature, did not protect the players against a decrease in their mood; moreover, they were associated with a worse affective state.

Our findings might be due to the nature of the sport whose players were examined: football is a team sport, where the responsibility for failure is in a way distributed among the players and thus may contribute to decreasing their self-esteem to a lesser extent. It would be useful to analyse these relationships taking into account the responsibility borne for the poor outcome by a particular player, both according to external observers and the player themselves.

If the relationships observed were more universal, it would be a good idea to further investigate the way the players' coaches work with them after matches. Since negative mood was associated with external attributions, the coaches should consider helping the players develop internal attributions. This is something that has been emphasised by other authors [14, 21].

The results of our study showed that the football players had a tendency to attribute success to internal causes and failure to external ones. Based on these findings, it can be hypothesised that more frequent use of external attributions had an adverse effect on the mood states of the players.

Owing to the small size of the group of subjects and the fact that the sample examined in the study was not representative of Polish football players, the findings cannot be generalised to the entire population of male football players. They can, however, be useful in further research aimed at confirming the relationships identified in the current study.

Having information regarding an athlete's mental states can improve the collaboration between the coach and the athlete and it can also be useful in training the athlete and supporting them in moments of difficulty in their sports career. Researchers should continue to investigate the relationships between the cognitive sphere (attributions) and affective states experienced after sporting events in different disciplines, in particular individual ones. It might also be useful to measure the variables discussed above in larger groups of players in order to observe the trends in the data.

The findings of our study also have several practical applications. We believe that the coach should discuss the causal attributions of the outcome of a sporting event with the player. An appropriate analysis of the components of the player's performance carried out together with the coach can help the player better prepare for future matches, learn more about themselves, and draw more valid conclusions about what they need to work on in the future. Thus knowing a given player's attributions can be useful for the coaching team, in that it can be helpful in assisting the player in achieving better outcomes and developing their abilities. An adequate discussion with the player after the match which includes both the positive and negative elements of their performance can also help them alleviate excessive negative emotions.

If coaches acquire the ability to describe and explain the psychosocial aspects of sports activity as well as predict changes in the psychological state of the athlete and support them mentally, the athlete will have a chance to become fully engaged, exert control over their actions, and carry them out effectively [22].

It should be noted that beliefs related to attributions can be modified. It is worth considering the benefits of helping athletes to make internal attributions in the case of success and external attributions in situations of failure. Internal attributions can be encouraged after an important successful performance among others by emphasising the role of the effort made or the skills displayed by the athlete during the event.

\section{Literature}

1. Dąbrowska H. (1991). Motivation and sports performance. In T. Tyszka (ed.), Psychology and sport (pp. 28-54). Warsaw: AWF. [in Polish]

2. Gracz J., Sankowski T. (2007). Psychology of sports activity. Poznań: AWF. [in Polish]

3. Jarvis M. (2003). Psychology of sport. Gdańsk: Gdańskie Wydawnictwo Psychologiczne. [in Polish]

4. Lau R.R., Russell D. (1980). Attribution in the sports pages: A field test of same current hypotheses about attribution research. Journal of Personality and Social Psychology 39, 29-38.

5. McAuley E., Gross J.B. (1983). Perceptions of causality in sport: An application of the Causal Dimension Scale. Journal of Sport Psychology 5, 72-76. 
6. Biddle S.J.H., Hill A.B. (1992). Relationship between attributions and emotions in a laboratory-based sporting contest. Journal of Sports Sciences 10(1), 65-75.

7. Greenlees I.A., Lane A., Thelwell R., Holder T., Hobson G. (2005). Team-referent attributions among sport performers. Research Quarterly for Exercise and Sport 76, 477487.

8. Mroczkowska H. (2007). Psychosocial capacity for goal achievement in teams. Medycyna Sportowa 3(6), 135-139. [in Polish]

9. Orbach I., Singer R.N., Murphy M. (1997). Changing attributions with an attribution training technique related to basketball dribbling. The Sport Psychologist 11, 294-304.

10. Orbach I., Singer R.N., Price S. (1999). An attribution training programme and achievement in sport. The Sport Psychologist 13, 69-82.

11. Graham T.R., Kowalski K.C., Crocker P.R.E. (2002). The contributions of goal characteristics and causal attributions to emotional experience in youth sport participants. Psychology of Sport and Exercise 3, 273-291.

12. Biddle S.J.H., Hill A.B. (1988). Causal attributions and emotional reactions to outcome in a sporting contest. Personality and Individual Differences 9(2), 213-223.

13. Allen M., Jones M.V., Sheffield D. (2009). Causal attribution and emotion in the days following competition. Journal of Sports Sciences 27(5), 461-468.

14. Zinsser N., Bunker L., Williams J.M. (2010). Cognitive techniques for building confidence and enhancing performance. In J.M. Williams (ed.), Applied sport psychology: Personal growth to peak performance (pp. 305-335). New York: McGraw-Hill Companies.
15. Allen M., Jones M.V., Sheffield D. (2010). The influence of positive reflection on attributions, emotions, and selfefficacy. The Sport Psychologist 24, 211-226.

16. Rascle O., Le Foll D., Chamier M., Higgins N., Rees T., Coffee P. (2015). Durability and generalization of attribution-based feedback following failure: Effects on expectations and behavioral persistence. Psychology of Sport and Exercise 18, 68-74.

17. Coffee P., Rees T. (2009). The main and interactive effects of immediate and reflective attributions upon subsequent self-efficacy. European Journal of Sport Science 9, 41-52.

18. Dudek B., Koniarek J. (1987). An adaptation of the Profile of Mood States (POMS) test by D.M. McNair, M. Lorr, and L.F. Droppleman. Przegląd Psychologiczny 3, 753-762. [in Polish]

19. Mroczkowska H. (2001). Task and ego motivation: The evaluation of one's capacities and chances of success in women and men. Wychowanie Fizyczne i Sport 3, 289-297. [in Polish]

20. Doliński D., Szmajke A. (1991). Psychological response to participating in a sporting event. In T. Tyszka (ed.), Psychology and sport (pp. 113-152). Warsaw: AWF. [in Polish]

21. Le Foll D., Rascle O., Higgins N. (2008). Attributional feedback-induced changes in functional and dysfunctional attributions, expectations of success, hopefulness, and shortterm persistence in a novel sport. Psychology of Sport and Exercise 9(2), 77-101.

22. Gracz J. (2015). Psychological training - psychology of sport activity. In H. Sozański, J. Sadowski, J. Czerwiński (eds), Fundamentals of sports training theory and technology. (vol. 2). (pp. 230-259). Warszawa-Biała Podlaska: AWF. [in Polish]

Submitted: July 19, 2016

Accepted: October 28, 2016 